\title{
PERTUMBUHAN DAN HASIL PADI SAWAH ORGANIK DENGAN MENGGUNAKAN PUPUK KANDANG SAPI DAN AZOLLA
}

\author{
Mujiyo $^{1)}$, Bambang Hendro Sunarminto ${ }^{2)}$, Eko Hanudin ${ }^{2)}$ dan Jaka Widada ${ }^{3)}$ \\ ${ }^{1)}$ Program Studi Ilmu Tanah, Fakultas Pertanian, Universitas Sebelas Maret, Surakarta \\ Email:mujiyo@staff.uns.ac.id \\ ${ }^{2)}$ Jurusan Ilmu Tanah, Fakultas Pertanian, Universitas Gadjah Mada, Yogyakarta \\ ${ }^{3)}$ Jurusan Mikrobiologi, Fakultas Pertanian, Universitas Gadjah Mada, Yogyakarta
}

\begin{abstract}
Farmyard manure and azolla are potential sources of organic fertilizer in organic paddy field. This study aimed to determine the effect of using farmyard manure and azolla on growth and yield of rice crop. The research method was field trial in an organic paddy field, Sukorejo Village, Sragen, Indonesia. Experimental design which used was a completely randomized block design with 9 kinds of treatment which are repeated in 3 blocks. These kind of treatments were the using of farmyard manure, azolla fertilizer, azolla inoculum, and the combinations which is based on the fulfillment of nutrient requirements of $120 \mathrm{~kg} \mathrm{~N} \mathrm{ha}$. Farmyard manure significantly increased the fresh weight of biomass (two-way ANOVA $F=3.13 p<0.05$ ), the weight of grains per panicle (two-way ANOVA $F=$ $3.36 p<0.05)$ and dry grain harvest (two-way ANOVA $F=3.71 p<0.05$ ). Azolla fertilizer significantly increased the plant height (two-way ANOVA $F=2.93 p<0.05$ ). Meanwhile azolla inoculum did not give significant effect on all parameters (both growth and yield). Dry grain harvest has very significant correlation with plant height $\left(0.68^{* *}\right)$; fresh weight of biomass $\left(0.79^{* * *}\right)$; weight of grains per panicle $\left(0.61^{* *}\right)$; and grain weight of 1,000 seeds $\left(0.48^{*}\right)$. The result of $F$ test and correlation analysis showed that farmyard manure significantly increases the dry grain harvest through its role on increasing the weight of fresh biomass and grain weight per panicle. Azolla fertilizer also significantly increased the dry grain harvest through its role on increasing the plant height. However, the effect of Azolla fertilizer to increase the dry grain harvest was weaker than farmyard manure.
\end{abstract}

Keywords: organic paddy field, rice yield

\section{PENDAHULUAN}

Indonesia sebagai negara tropika pada umumnya mempunyai tanah dengan kandungan C-organik rendah yang disebabkan oleh tingginya suhu dan laju dekomposisi, serta kurangnya pengembalian bahan organik ke dalam tanah (Sanchez, 1976; Nieder and Benbi, 2008). Tanah sawah di Indonesia mempunyai kandungan bahan organik sangat rendah < 2\% Karama, 2001 ; Syamsiyah dan Mujiyo, 2006). Salah satu cara untuk mengatasi permasalahan tersebut dengan melakukan sistem padi sawah organik, yang salah satu komponen utamanya dengan penggunaan pupuk (bahan) organik. Namun demikian upaya melaksanakan sistem padi sawah organik tersebut mengalami kendala keberlanjutan penyediaan pupuk organik. Beberapa petani di Desa Sukorejo Kecamatan Sambirejo Kabupaten Sragen memberikan pupuk organik (pupuk kandang) dalam jumlah seadanya sesuai yang dipunyai oleh petani, tanpa ada penambahan sumber bahan organik lainnya. Pupuk organik (pupuk kandang sapi) yang diberikan oleh petani sangat bervariasi antara $1-5$ ton ha $^{-1}$ pada setiap musim tanam (Hartati, dkk., 2010; Mujiyo, dkk., 2010; Syamsiyah, dkk., 2010).

Hal tersebut disebabkan kurangnya kepemilikan ternak (ternak besar/sapi) oleh petani. Apabila lahan sawah organik diasumsikan menggunakan pupuk hanya dari kotoran ternak sapi, maka setiap 1 lahan harus didukung minimal oleh 4 ekor sapi (Syamsiyah dan Mujiyo, 2006). Luas sawah di Kecamatan Sambirejo sekitar 1.489 ha, sementara itu jumlah ternaknya sekitar 4.029 ekor (BPS Sragen, 2013). Jumlah ternak ideal untuk mendukung pertanian padi sawah organik di daerah ini sekitar 5.956 ekor, yang berarti masih kekurangan jumlah ternak sebanyak 1.927 ekor. Kendala lain adalah beberapa petani belum merasa puas kalau tanaman padi hanya dipupuk dengan pupuk kandang, karena biasanya tanaman tidak segera tumbuh subur, tidak tampak hijau, dan jumlah anakan sedikit. Beberapa petani untuk 
mengatasi masalah tersebut akhirnya masih menggunakan pupuk urea. Kebiasaan petani yang masih menggunakan pupuk kimia (urea) ini merupakan kendala bagi keberlanjutan standar produksi beras organik, sehingga perlu mendapat perhatian dan jalan pemecahan masalahnya.

Salah satu strategi yang dapat diterapkan untuk mengatasi permasalahan tersebut adalah dengan penggunaan azolla. Azolla dapat ditanam bersama-sama dengan tanaman padi, mampu menghasilkan biomassa yang besar dalam waktu singkat, mempunyai kemampuan menambat $\mathrm{N}_{2}$ udara, sehingga selain sebagai sumber bahan organik dapat digunakan juga sebagai pupuk $\mathrm{N}$, teknik ini lebih mudah dan murah untuk diaplikasikan ke lapangan (Arifin, 1996). Oleh karena itu perlu dilakukan penelitian bagaimana pertumbuhan dan hasil padi sawah organik dalam bentuk percobaan lapangan dengan menggunakan pupuk kandang sapi yang dikombinasikan dengan azolla.

\section{METODE PENELITIAN}

\section{Percobaan Lahan}

Penelitian ini dilaksanakan dengan metode experiment yaitu percobaan penanaman padi sawah di lahan sawah organik Desa Sukorejo, Sambirejo, Sragen. Pelaksanaan penanaman menyesuaikan dengan kebiasaan petani setempat. Jenis tanah Umbric Epiaqualf bertekstur lom (klei 24,56\%, debu $34,70 \%$, pasir 40,74\%) dengan sifat kimia : $\mathrm{pH}$ 6,2, kapasitas pertukaran kation 27,75 $\mathrm{cmol}$ (+) $\mathrm{kg}^{-1}$ tanah, kejenuhan basa $19,45 \%$, C-organik 2,09\% dan $\mathrm{N}$ total $0,15 \%$.

Tabel 1. Macam perlakuan percobaan

\begin{tabular}{|c|c|c|c|c|c|}
\hline \multirow{2}{*}{ Kode } & \multirow{2}{*}{ Keterangan Perlakuan } & \multicolumn{3}{|c|}{$\begin{array}{c}\text { Penyediaan N } \\
\left(\mathrm{kg} \mathrm{N} \mathrm{ha}^{-1}\right)\end{array}$} & \multirow{2}{*}{$\begin{array}{c}\text { Total } \\
\text { Penyediaar } \\
\mathrm{N} \\
\left(\mathrm{kg} \mathrm{N} \mathrm{ha}^{-1}\right)\end{array}$} \\
\hline & & PK & PA & IA & \\
\hline $\mathrm{A}$ & Kontrol (Tanpa N) & 0 & 0 & 0 & 0 \\
\hline B & PKS 8 ton $\mathrm{ha}^{-1}$ & 120 & 0 & 0 & 120 \\
\hline $\mathrm{C}$ & PA 5 ton ha $^{-1}$ & 0 & 120 & 0 & 120 \\
\hline $\mathrm{D}$ & IA 4 ton $\mathrm{ha}^{-1}$ & 0 & 0 & 120 & 120 \\
\hline $\mathrm{E}$ & PKS 4 ton $\mathrm{ha}^{-1}+$ PA 2,5 ton $\mathrm{ha}^{-1}$ & 60 & 60 & 0 & 120 \\
\hline $\mathrm{F}$ & PKS 4 ton $\mathrm{ha}^{-1}+$ IA 2 ton $\mathrm{ha}^{-1}$ & 60 & 0 & 60 & 120 \\
\hline G & PA 2,5 ton $\mathrm{ha}^{-1}+$ IA 2 ton $\mathrm{ha}^{-1}$ & 0 & 60 & 60 & 120 \\
\hline $\mathrm{H}$ & PKS 2,67 ton $\mathrm{ha}^{-1}+$ PA 1,67 ton $\mathrm{ha}^{-1}+$ IA 1,33 ton $\mathrm{ha}^{-1}$ & 40 & 40 & 40 & 120 \\
\hline I & PKS 8 ton $\mathrm{ha}^{-1}+$ PA 5 ton $\mathrm{ha}^{-1}+$ IA 4 ton $\mathrm{ha}^{-1}$ & 120 & 120 & 120 & 360 \\
\hline
\end{tabular}

PKS = pupuk kandang sapi, PA = pupuk azolla, IA = inokulum azolla, ditumbuhkan bersama tanaman padi. Total penyediaan $120 \mathrm{~kg} \mathrm{~N}^{-1}$ didasarkan dari kebutuhan tanaman padi sawah (Sanchez, 1976). Kandungan N pupuk kandang sapi 1,2\% (Syamsiyah, dkk., 2010, Mujiyo, dkk., 2010 dan Hartati, dkk., 2010). Asumsi efisiensi pemupukan 80\%. Kandungan N pupuk azolla (segar) 2\% (Mujiyo, dkk., 2010 dan Hartati, dkk., 2010). Asumsi efisiensi pemupukan $80 \%$. Inokulum azolla 1 ton ha ${ }^{-1}$ yang diaplikasikan 5 hari setelah tanam padi, selama 30 hari (pada saat tanaman padi masa puncak pertumbuhan vegetatif) akan dapat menyediakan $30 \mathrm{~kg} N$ ha $^{-1}$ (Bharati, et al., 2000).

Rancangan percobaan menggunakan RAKL (Rancangan Acak Kelompok Lengkap) (Steel and Torie, 1980) dengan 9 (sembilan) macam perlakuan yang masing-masing diulang 3 blok. Masing-masing blok seluas $90 \mathrm{~m}^{2}(2 \mathrm{~m}$ x $45 \mathrm{~m}$ ) dibagi 9 plot (petak) sesuai jumlah perlakuan, dengan pembatas berupa pematang dengan konstruksi baik. Masing-masing plot satuan percobaan luas $10 \mathrm{~m}^{2}(2 \mathrm{~m} \times 5 \mathrm{~m})$. Saluran air masuk dirancang terisolasi antar plot perlakuan, dibuat sepanjang blok dan air masuk ke plot perlakuan melalui pintu masingmasing. Saluran pembuangan air dirancang langsung ke luar lahan dan tidak masuk ke plot perlakuan lainnya.

Masing-masing blok terletak pada bidang lahan yang sama, dengan ukuran lebar $2 \mathrm{~m}$ dan panjang $45 \mathrm{~m}$, dan ditambah untuk tanaman pagar dan saluran air masuk dan keluar. Blok I sampai dengan III ditempatkan secara berurutan pada bidang/teras lahan dari atas ke bawah yang menyesuaikan dengan kondisi lahan. Pupuk kandang sapi dan pupuk azolla sesuai perlakuan diberikan 3 (tiga) hari sebelum tanam (HST), dicampur merata ke dalam lapisan olah tanah. Inokulum azolla ditebar secara merata 5 (lima) hari setelah 
tanam padi. Penanaman dilakukan setelah bibit berumur 21 hari, 3 bibit per lubang dengan jarak tanam $20 \mathrm{~cm}$ x $20 \mathrm{~cm}$. Air dijaga ketinggiannya $\pm 5 \mathrm{~cm}$ sampai dengan panen.

\section{Pengukuran Parameter Pertumbuhan dan Hasil Tanaman}

Pewakil tanaman diambil 4 rumpun setiap satuan percobaan. Tinggi tanaman ditentukan dengan mengukur tinggi bagian pangkal batang sampai dengan ujung daun terpanjang. Jumlah anakan total dengan menghitung banyaknya semua anakan (batang). Jumlah anakan produktif ditentukan dengan cara menghitung banyaknya total anakan produktif (anakan yang menghasilkan malai). Berat gabah per malai ditentukan dengan menimbang gabah yang dihasilkan sewaktu panen setiap malai. Berat gabah 1.000 biji ditentukan dengan menimbang berat gabah panen sebanyak 1.000 biji. Berat segar brangkasan (BSB) ditentukan dengan menimbang berat tanaman bagian atas tanah setelah gabah dirontokkan. Gabah kering panen (GKP) ditentukan dengan menimbang berat gabah setelah dirontokkan pada saat panen. Indek panen (IP) ditentukan dengan rumus perhitungan sebagai berikut ;

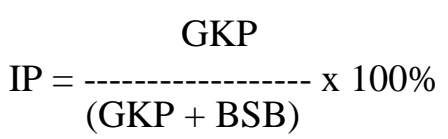

(Bharati, et al. 2000)

\section{Analisis Statistik}

Analisa data dengan menggunakan uji $\mathrm{F}$ (two-way ANOVA), dan apabila ada beda nyata dilanjutkan dengan Duncan's Multiple Range Test (DMRT) dengan taraf kepercayaan 95\% untuk mengetahui perbedaan antar rerata perlakuan. Penentuan keeratan hubungan antara parameter pertumbuhan dan hasil tanaman menggunakan analisis korelasi (Steel and Torie, 1980).

\section{HASIL DAN PEMBAHASAN}

Data pertumbuhan dan hasil tanaman tersaji pada tabel 2 dan 3. Tinggi tanaman dan jumlah anakan relatif berbeda tidak nyata antar perlakuan pada semua umur tanaman (tabel 2). Hasil penelitian ini sama dengan yang diperoleh pada penelitian oleh Arsana (2012), perlakuan pengairan (terus-menerus, 4 hari sekali, 8 hari sekali) terhadap varietas padi Mekongga, Inpari 1 dan Inpari 10Laeya yang dilakukan di bagian hulu, tengah dan hilir DAS Yeh Ho Provinsi Bali menghasilkan tinggi tanaman dan jumlah anakan yang berbeda tidak nyata pada MT 1 dan 2 .

Tinggi tanaman pada umur 70 HST ada perbedaan nyata antara perlakuan A (kontrol, tanpa pupuk) dengan perlakuan lainnya. Hal ini disebabkan pada perlakuan kontrol tidak ada masukan unsur hara, sehingga tinggi tanamannya lebih rendah. Jumlah anakan sementara itu berbeda tidak nyata antar perlakuan pada semua umur tanaman. Jumlah anakan yang dihasilkan pada perlakuan A ada kecenderungan lebih banyak dari pada perlakuan lainnya, tetapi ukurannya lebih kecil. Perlakuan A dengan tidak adanya masukan unsur hara, walaupun anakan terbentuk tetapi perkembangan selanjutnya terhambat, sehingga ukuran anakan tidak bisa berkembang.

Jumlah anakan pada blok III secara nyata lebih rendah dari pada blok I dan II (tabel 3). Hal ini disebabkan pada blok III posisi lahannya lebih di bawah dan air genangan lebih stabil. Tanaman padi sawah yang tergenang terus-menerus cenderung akan membentuk anakan yang lebih sedikit (Ohe et. 2010; Omwenga et al. 2014). Hal ini terkait dengan semakin banyaknya energi yang diperlukan tanaman untuk mencukupi kebutuhan $\mathrm{O}_{2}$ apabila tanah selalu tergenang, sehingga berdampak jumlah anakan semakin sedikit. 
Tabel 2. Tinggi tanaman dan jumlah anakan

\begin{tabular}{|c|c|c|c|c|c|c|c|c|}
\hline \multirow{2}{*}{ No. } & \multirow{2}{*}{ Perlakuan } & \multicolumn{3}{|c|}{ Tinggi Tanaman $(\mathrm{cm})$} & \multicolumn{4}{|c|}{ Jumlah Anakan (Batang) } \\
\hline & & $40 \mathrm{HST}$ & $70 \mathrm{HST}$ & 90 HST & $40 \mathrm{HST}$ & $70 \mathrm{HST}$ & $90 \mathrm{HST}$ & Produktif \\
\hline 1. & $\mathrm{~A}$ & $54,5 \mathrm{a}$ & $68,0 \mathrm{a}$ & $82,5 \mathrm{a}$ & $24 a$ & $21 \mathrm{a}$ & $15 \mathrm{a}$ & $13 a$ \\
\hline 2. & B & $66,9 a$ & $87,2 \mathrm{~b}$ & $95,2 \mathrm{a}$ & $25 \mathrm{a}$ & $20 \mathrm{a}$ & $16 \mathrm{a}$ & $14 \mathrm{a}$ \\
\hline 3. & $\mathrm{C}$ & $63,1 \mathrm{a}$ & $84,7 \mathrm{ab}$ & $94,5 \mathrm{a}$ & $22 \mathrm{a}$ & $19 \mathrm{a}$ & $16 \mathrm{a}$ & $12 \mathrm{a}$ \\
\hline 4. & $\mathrm{D}$ & $57,8 \mathrm{a}$ & $77,4 \mathrm{ab}$ & $89,7 \mathrm{a}$ & $21 \mathrm{a}$ & $20 \mathrm{a}$ & $16 a$ & $14 a$ \\
\hline 5. & $\mathrm{E}$ & $59,8 \mathrm{a}$ & $79,4 \mathrm{ab}$ & $92,8 \mathrm{a}$ & $21 \mathrm{a}$ & $20 \mathrm{a}$ & $17 \mathrm{a}$ & $14 \mathrm{a}$ \\
\hline 6. & $\mathrm{~F}$ & $63,9 a$ & $79,6 \mathrm{ab}$ & $94,7 \mathrm{a}$ & $22 \mathrm{a}$ & $19 \mathrm{a}$ & $16 \mathrm{a}$ & $14 \mathrm{a}$ \\
\hline 7. & G & $64,0 \mathrm{a}$ & $83,8 \mathrm{ab}$ & $98,1 \mathrm{a}$ & $22 \mathrm{a}$ & $19 a$ & $16 \mathrm{a}$ & $14 \mathrm{a}$ \\
\hline 8. & $\mathrm{H}$ & $63,3 \mathrm{a}$ & $81,1 \mathrm{ab}$ & $91,6 a$ & $22 \mathrm{a}$ & $19 \mathrm{a}$ & $15 \mathrm{a}$ & $13 a$ \\
\hline 9. & I & $65,4 a$ & $88,2 \mathrm{~b}$ & $98,9 a$ & $21 \mathrm{a}$ & $19 \mathrm{a}$ & $15 \mathrm{a}$ & $13 a$ \\
\hline \multicolumn{2}{|c|}{ Rata-Rata } & 62,1 & 81,0 & 93,1 & 22 & 20 & 16 & 13 \\
\hline No. & Blok & & & & & & & \\
\hline 1. & I & $64,24 a$ & $82,57 \mathrm{a}$ & $94,00 \mathrm{a}$ & $24 b$ & $21 b$ & $17 \mathrm{~b}$ & $15 b$ \\
\hline 2. & II & $61,84 a$ & $79,44 a$ & $95,20 \mathrm{a}$ & $24 b$ & $22 b$ & $17 \mathrm{~b}$ & $14 \mathrm{~b}$ \\
\hline 3. & III & $60,14 \mathrm{a}$ & $81,13 \mathrm{a}$ & $90,21 \mathrm{a}$ & $19 \mathrm{a}$ & $16 \mathrm{a}$ & $14 \mathrm{a}$ & $12 \mathrm{a}$ \\
\hline
\end{tabular}

Angka yang diikuti notasi huruf sama berbeda tidak nyata pada taraf $5 \%$.

Berat gabah 1.000 biji pada semua perlakuan berbeda tidak nyata, rata-rata 27,48 gram (tabel 3). Deskripsi tanaman padi varietas IR-64 menurut Departemen Pertanian Republik Indonesia menyebutkan bahwa ratarata berat 1.000 biji sebesar 27 gram (Balai Besar Penelitian Padi, 2008). Hal ini berarti hasil gabah pada semua perlakuan mempunyai kualitas sedikit lebih baik dari rata-rata nasional. Kondisi lahan yang lebih baik dengan indikator kandungan C-organik > 2\% diduga yang berpengaruh baik terhadap kualitas gabah.

Tabel 3. Berat segar brangkasan (BSB), berat gabah per malai (BGM), berat gabah 1.000 biji (B 1.000), gabah kering panen (GKP) dan indeks panen (IP)

\begin{tabular}{ccccccc}
\hline No. & Perlakuan & $\begin{array}{c}\text { BSB } \\
\left(\text { ton } \mathrm{ha}^{-1}\right)\end{array}$ & $\begin{array}{c}\text { BGM } \\
(\text { gram })\end{array}$ & $\begin{array}{c}\text { B 1.000 } \\
(\text { gram })\end{array}$ & $\begin{array}{c}\text { GKP } \\
\left(\text { ton ha }^{-1}\right)\end{array}$ & $\begin{array}{c}\text { IP } \\
(\%)\end{array}$ \\
\hline 1. & A & $20,03 \mathrm{a}$ & $1,98 \mathrm{a}$ & $25,83 \mathrm{a}$ & $7,29 \mathrm{a}$ & $26,54 \mathrm{a}$ \\
2. & $\mathrm{~B}$ & $29,29 \mathrm{~b}$ & $3,05 \mathrm{bcd}$ & $26,94 \mathrm{a}$ & $9,83 \mathrm{~b}$ & $25,10 \mathrm{a}$ \\
3. & $\mathrm{C}$ & $25,14 \mathrm{ab}$ & $3,01 \mathrm{bcd}$ & $27,96 \mathrm{a}$ & $9,26 \mathrm{ab}$ & $26,96 \mathrm{a}$ \\
4. & $\mathrm{D}$ & $23,32 \mathrm{ab}$ & $2,60 \mathrm{~b}$ & $26,56 \mathrm{a}$ & $8,09 \mathrm{ab}$ & $26,06 \mathrm{a}$ \\
5. & $\mathrm{E}$ & $25,57 \mathrm{ab}$ & $2,67 \mathrm{bc}$ & $27,96 \mathrm{a}$ & $9,40 \mathrm{ab}$ & $27,39 \mathrm{a}$ \\
6. & F & $28,51 \mathrm{~b}$ & $3,02 \mathrm{bcd}$ & $28,34 \mathrm{a}$ & $9,57 \mathrm{ab}$ & $25,14 \mathrm{a}$ \\
7. & $\mathrm{G}$ & $27,11 \mathrm{~b}$ & $2,79 \mathrm{bcd}$ & $28,62 \mathrm{a}$ & $9,16 \mathrm{ab}$ & $25,14 \mathrm{a}$ \\
8. & $\mathrm{H}$ & $27,80 \mathrm{~b}$ & $3,16 \mathrm{~cd}$ & $28,05 \mathrm{a}$ & $9,51 \mathrm{ab}$ & $25,52 \mathrm{a}$ \\
9. & $\mathrm{I}$ & $28,16 \mathrm{~b}$ & $3,20 \mathrm{~d}$ & $27,07 \mathrm{a}$ & $10,18 \mathrm{~b}$ & $26,58 \mathrm{a}$ \\
\hline & Rata-Rata & 26,10 & 2,83 & 27,48 & 9,14 & 26,05 \\
\hline No. & Blok & & & & \\
\hline 1. & I & $27,86 \mathrm{~b}$ & $2,83 \mathrm{a}$ & $27,71 \mathrm{ab}$ & $9,86 \mathrm{~b}$ & $26,28 \mathrm{a}$ \\
2. & II & $26,64 \mathrm{ab}$ & $2,70 \mathrm{a}$ & $26,50 \mathrm{a}$ & $9,04 \mathrm{ab}$ & $25,26 \mathrm{a}$ \\
3. & III & $23,82 \mathrm{a}$ & $2,97 \mathrm{a}$ & $28,25 \mathrm{~b}$ & $8,53 \mathrm{a}$ & $26,60 \mathrm{a}$ \\
\hline
\end{tabular}

Angka yang diikuti notasi huruf yang sama berbeda tidak nyata pada taraf 5\%. 
Tabel 4. Korelasi terpilih parameter hasil dan pertumbuhan tanaman

\begin{tabular}{cccccccc}
\hline & TT & AT & AP & BSB & BGM & B 1.000 & GKP \\
\hline AT & $0,40^{*}$ & & & & & & \\
AP & $0,35^{\text {ns }}$ & $0,93^{* *}$ & & & & & \\
BSB & $0,71^{* *}$ & $0,65^{* *}$ & $0,35^{\text {ns }}$ & & & & \\
BGM & $0,50^{* *}$ & $-0,30^{\text {ns }}$ & $-0,29^{\text {ns }}$ & $0,39^{*}$ & & & \\
B 1.000 & $0,50^{*}$ & $-0,31^{\text {ns }}$ & $-0,29^{\text {ns }}$ & $0,39^{*}$ & $0,67^{* *}$ & & \\
GKP & $0,68^{* *}$ & $0,29^{\text {ns }}$ & $0,31^{\text {ns }}$ & $0,79^{* *}$ & $0,61^{* *}$ & $0,48^{*}$ & \\
IP & $-0,19^{\text {ns }}$ & $-0,61^{* *}$ & $-0,56^{* *}$ & $-0,49^{* *}$ & $0,24^{\text {ns }}$ & $0,35^{\text {ns }}$ & $0,14^{\text {ns }}$ \\
\hline
\end{tabular}

Notasi ${ }^{\text {ns }}=$ tidak nyata, ${ }^{*}=$ nyata, ${ }^{* *}=$ sangat nyata

$\mathrm{TT}=$ tinggi tanaman, $\mathrm{AT}=$ anakan total, $\mathrm{AP}=$ anakan produktif, $\mathrm{BSB}=$ berat segar brangkasan, $\mathrm{BGM}=$ berat gabah per malai, $\mathrm{B} 1.000$ = berat gabah 1.000 biji, $\mathrm{GKP}=$ gabah kering panen, $\mathrm{IP}=$ indeks panen.

Indeks panen pada semua perlakuan berbeda tidak nyata. Gabah kering panen dan berat segar brangkasan walaupun berbeda nyata antar perlakuan, tetapi indeks panennya berbeda tidak nyata. Hal ini menunjukkan bahwa setiap peningkatan berat segar brangkasan akan diikuti dengan peningkatan hasil gabah kering panen, demikian juga sebaliknya, sehingga indeks panen akan berbeda tidak nyata.

Hasil gabah kering panen berbeda nyata antar perlakuan, perlakuan B dan I rata-rata menghasilkan tertinggi dan berbeda nyata dengan kontrol. Perlakuan C, D, E, F, G dan H ada kecenderungan lebih tinggi dari kontrol dan berbeda tidak nyata dengan perlakuan B dan I. Perlakuan I merupakan perlakuan yang memberikan dosis penuh pupuk kandang sapi (120 kg N ha-1), pupuk azolla (120 $\mathrm{kg} \mathrm{N} \mathrm{ha}^{-1}$ ) dan inokulum azolla $\left(120 \mathrm{~kg} \quad \mathrm{~N} \quad \mathrm{ha}^{-1}\right)$, menghasilkan GKP relatif paling tinggi, tetapi perbedaannya tidak nyata. Hal ini menunjukkan bahwa perlakuan tersebut sudah melewati batas dosis optimum.Pupuk kandang sapi berpengaruh nyata meningkatkan berat segar brangkasan (two-way ANOVA $\mathrm{F}=3,13$ $\mathrm{p}<0,05$ ), berat gabah per malai (two-way ANOVA $F=3,36 p<0,05)$ dan gabah kering panen (two-way ANOVA $F=3,71 p<0,05$ ). Pupuk azolla berpengaruh nyata meningkatkan tinggi tanaman (two-way ANOVA $\mathrm{F}=2,93 \mathrm{p}$ $<$ 0,05). Sementara itu inokulum azolla berpengaruh tidak nyata terhadap semua parameter pertumbuhan dan hasil tanaman. Hasil gabah kering panen berkorelasi sangat nyata dengan tinggi tanaman $\left(0,68^{* *}\right)$, berat segar brangkasan $\left(0,79^{* * *}\right)$ dan berat gabah per malai $\left(0,61^{* *}\right)$, berkorelasi nyata dengan berat gabah 1.000 biji $\left(0,48^{*}\right)$, sementara itu berkorelasi tidak nyata dengan jumlah anakan $\left(0,29^{\text {ns }}\right)$ (tabel 4$)$. Tanaman yang tinggi dan mempunyai brangkasan yang lebih besar merupakan indikator bagi tanaman yang dapat menyelengarakan proses fotosintesa yang tinggi (Varon and Diaz, 2015), sehingga juga akan menghasilkan gabah per malai dan berat biji gabah yang tinggi, dan berdampak kepada hasil gabah yang tinggi pula (Makino, 2011). Sementara itu jumlah anakan yang tinggi belum tentu dapat menghasilkan gabah yang tinggi, karena ada kemungkinan jumlah anakan yang tinggi berdampak kepada gabah per malai yang rendah. Hal ini disebabkan pada rumpun dengan jumlah anakan yang tinggi akan terjadi persaingan internal untuk pertumbuhannya.

Hasil analisis uji $\mathrm{F}$ dan korelasi tersebut menunjukkan bahwa pupuk kandang sapi berpengaruh nyata meningkatkan hasil gabah kering panen melalui peranannya meningkatkan berat segar brangkasan dan berat gabah per malai. Pupuk azolla juga berpengaruh nyata meningkatkan hasil gabah kering panen melalui peranannya meningkatkan tinggi tanaman. Namun pengaruh pupuk azolla terhadap peningkatan hasil gabah kering panen lebih lemah dari pada pupuk kandang sapi.

\section{KESIMPULAN}

Pupuk kandang sapi berpengaruh nyata meningkatkan hasil gabah kering panen. Pupuk kandang sapi berpengaruh meningkatkan berat segar brangkasan dan berat gabah per malai yang kemudian berdampak meningkatkan hasil gabah kering panen. Pupuk azolla juga berpengaruh nyata meningkatkan hasil gabah kering panen. Pupuk azolla berpengaruh meningkatkan tinggi tanaman yang kemudian berdampak meningkatkan hasil gabah kering panen. Pengaruh pupuk azolla terhadap peningkatan hasil gabah kering panen lebih lemah dari pada pupuk kandang sapi. Sementara itu 
penggunaan inokulum azolla (azolla yang ditanam bersama dengan tanaman padi) tidak berpengaruh terhadap pertumbuhan dan hasil tanaman.

\section{UCAPAN TERIMAKASIH}

Penulis mengucapkan terimakasih kepada Dirjen Dikti yang telah memfasiltasi penelitian untuk program Doktor tahun 2012-2014. Penulis juga mengucapkan terimakasih kepada Dik Nukhak dan Dik Demi atas segala bantuan dalam melaksanakan penelitian, dan kepada laboran Mas Yen, Mas Sidik, Mbak Tum, Mas Darsono dan Dik Nita atas bantuan selama analisis di laboratorium.

\section{DAFTAR PUSTAKA}

Arifin, Z. 1996. Azolla, Pembudidayaan dan Pemanfaatan pada Tanaman Padi. Penebar Swadaya. Jakarta.

Arsana, I. G. K. D. 2012. Efisiensi pemanfaatan air tanaman padi pada bagian hulu, tengah dan hilir daerah aliran sungai Yeh Ho Provinsi Bali. Disertasi. Program Pascasarjana. Fakultas Pertanian. Universitas Gadjah Mada. Yogyakarta.

Balai Besar Penelitian Tanaman Padi. 2008. Deskripsi Padi Varietas IR64. Departemen Pertanian Republik Indonesia.

Bharati, K., S. R. Mohanty, D. P. Singh, V. R. Rao, and T. K. Adhya. 2000 Influence of incorporation or dual cropping of Azolla on methane emission from a flooded alluvial soil planted to rice in Eastern India. Agriculture, Ecosystems \& Environment Volume 79, Issue 1, Pages $73-83$.

BPS Sragen. 2013. Kecamatan Sambirejo dalam Angka Tahun 2012. Badan Pusat Statistik Kabupaten Sragen.

Hartati, S., H. Widijanto, dan D. P. Ariyanto, 2010. Dual system Azolla - Padi : sebagai strategi mitigasi emisi grk metana di lahan padi organik Kabupaten Sragen. Laporan Penelitian. DIPA BLU FP UNS TA 2010.

Karama, S. 2001. Pertanian organik Indonesia kini dan nanti. Makalah Seminar. Disajikan pada Seminar Penggunaan Cendawan Mikoriza dalam Sistem
Pertanian Organik dan Rehabilitasi Lahan Kritis. UNPAD Bandung.

Makino, A. 2011. Photosynthesis, grain yield, and nitrogen utilization in rice and wheat. Plant Physiology. Vol. 155 No. 1: 125129.

Mujiyo, J. Syamsiyah, J., B. H. Sunarminto. 2010. Mitigasi emisi GRK (Gas Rumah Kaca) sebagai strategi menjaga keberlanjutan produksi padi organik di Kabupaten Sragen. Laporan Penelitian Hibah Penelitian Strategis Nasional. Dikti TA 2010.

Nieder, R., and D. K. Benbi. 2008. Carbon and nitrogen in the terrestrial environment. springer science + Bussines Media B. V.

Ohe, M., N. Okita, and H. Daimon. 2010. Effects of deep-flooding irrigation on growth, canopy structure and panicle weight yield under different planting patterns in rice. Plant Production Science, (13:2): 193-198.

Omwenga, K. G., B. M. Mati, and P. G. Home. 2014. Determination of the effect of the system of rice intensification (SRI) on rice yields and water saving in Mwea Irrigation Scheme, Kenya. Journal of Water Resource and Protection, 2014 (6): 895-901.

Sanchez, P. A. 1976. Properties and Management of Soils in The Tropics. A Wiley-Intersscience Publication. John Wiley and Sons. New York. London. Sydney. Toronto.

Steel, R. G. D., and J. H. Torrie. 1980. Principles and procedures of statistics, a biometrical approach. McGraw Hill, New York.

Syamsiyah, J. dan Mujiyo. 2006. Studi reklamasi lahan sawah berkadar bahan organik rendah. laporan kegiatan. Kerjasama Direktorat Pengelolaan Lahan, Direktorat Jenderal Pengelolaan Lahan dan Air, Departemen Pertanian RI dengan Fakultas Pertanian, Universitas Sebelas Maret, Surakarta.

Syamsiyah, J., B. H. Sunarminto, dan Mujiyo. 2010. Pemetaan "Carbon Budget" sebagai dasar strategi mitigasi emisi karbondioksida $\left(\mathrm{CO}_{2}\right)$ dan metana $\left(\mathrm{CH}_{4}\right)$ 
di lahan padi sawah organik Kabupaten Sragen. Laporan Penelitian Program Insentif Riset Dasar Kementerian Negara Riset dan Teknologi TA 2010.
Varon, G. G., and H. R. Díaz. 2015. Growth and yield of rice cultivars sowed on different dates under tropical conditions. Ciencia e investigación agraria. 42(2):217-226. 